\title{
Kinetics study on supercritical fluid extraction of zinc(II) ion from aqueous solutions
}

\author{
Clifford Y. Tai *, Geng-Shian You, Shih-Lung Chen \\ Department of Chemical Engineering, National Taiwan University, Taipei, Taiwan 10617 ROC \\ Received 21 November 1999; received in revised form 11 May 2000; accepted 20 June 2000
}

\begin{abstract}
This work studies the kinetics of metal ion extraction using an in situ chelation-SFE method with Cyanex 302 as the chelating agent, which is commercially available, and supercritical carbon dioxide as the solvent, which extracts the metal-chelate complex from aqueous solutions. Zinc(II) ion is studied as a model species. The experiments are conducted in a $1.3-\mathrm{dm}^{3}$ batch stirred tank. The effects of pressure and stirring rate were investigated. The extraction efficiency at $313 \mathrm{~K}$ varies from 50 to $60 \%$ when the pressure varies from 8.3 to $13.8 \mathrm{MPa}$. A simplified model is used to estimate the effective mass-transfer coefficient. The results show that the extraction rate of zinc(II) ion increases with an increase in stirring rate, but decreases with pressure. The effective mass-transfer coefficient at $313 \mathrm{~K}$ and 8.3 $\mathrm{MPa}$ varies from 0.45 to $2.6 \times 10^{-3} \mathrm{~s}^{-1}$ when the stirring rate increases from 7.2 to $17.7 \mathrm{~s}^{-1}$. (C) 2000 Elsevier Science B.V. All rights reserved.
\end{abstract}

Keywords: Supercritical fluid extraction; Carbon dioxide; Zinc ion; Chelation; Mass-transfer coefficient; Stirred tank

\footnotetext{
Abbreviations: $a$, area of mass-transfer surface per unit volume of aqueous phase, $\mathrm{m}^{2} / \mathrm{m}^{3} ; C_{\mathrm{M}}^{\mathrm{F}}$, concentration of metal species (metal complex) in $\mathrm{SC} \mathrm{CO}_{2}$ phase, $\mathrm{mol} / \mathrm{m}^{3} ; C_{\mathrm{M}}^{\mathrm{L}}$, concentration of metal species (metal ion) in aqueous phase, $\mathrm{mol} / \mathrm{m}^{3} ; d$, impeller diameter, $\mathrm{m} ; D$, diffusion coefficient, $\mathrm{m}^{2} / \mathrm{s}$; $k$, mass-transfer coefficient, $\mathrm{m} / \mathrm{s} ; K_{\mathrm{F}}, \mathrm{SCF}$-side overall masstransfer coefficient, $\mathrm{m} / \mathrm{s} ; K_{\mathrm{F}} a, \mathrm{SCF}$-side effective overall masstransfer coefficient, $\mathrm{s}^{-1} ; m$, equilibrium distribution coefficient $\left(C_{\mathrm{M}, \infty}^{\mathrm{F}} / C_{\mathrm{M}, \infty}^{\mathrm{L}}\right) ; N$, stirring rate, $\mathrm{s}^{-1} ; N_{\mathrm{M}}$, molar flux per unit surface area, $\mathrm{mol} / \mathrm{m}^{2} \cdot \mathrm{s} ; P$, pressure, $\mathrm{MPa} ; \mathrm{Re}$, Reynolds number $\left(N d^{2} \rho / \mu\right)$; Sc, Schmidt number $(\mu / \rho D)$; Sh, Sherwood number $(k d / D) ; t$, time, $\mathrm{s} ; V$, phase volume, $\mathrm{m}^{3} ; \alpha$, slope in Eq. 9; $\mu$, viscosity, $\mathrm{kg} / \mathrm{m} \cdot \mathrm{s} ; \rho$, density, $\mathrm{kg} / \mathrm{m}^{3}$.

* Corresponding author. Tel.: + 886-2-23620832; fax: + 886-2-23623040.

E-mail address: cytai@ccms.ntu.edu.tw (C.Y. Tai).
}

\section{Introduction}

The presence of heavy metals in water and wastewater is an issue of increasing importance because of their hazardous properties to human beings, such as toxicity, persistence, bioaccumulation, and carcinogenicity. For example, zinc is one of the heavy metals that exists in the discharged wastewater from chemical plants that severely contaminates rice, soil, and groundwater in Taiwan [1]. The most widely used process to remove heavy metals is generally accomplished by the precipitation process [2]. However, the precipitation process usually results in contaminated sludge that has to be landfilled, which later makes 
groundwater polluted. Although other methods are available for the removal or recovery of heavy metals such as conventional solvent extraction, crystallization in a pellet reactor [3,4], adsorption onto activated carbon [5], electrochemical methods, and biochemical methods, there are inherent limitations in each of them. For example, extraction and stripping (reverse extraction) efficiency in the conventional solvent extraction process is limited by the equilibrium distribution coefficient of the solute between phases and the high ratio of solvent to feed; the regeneration of activated carbon usually consumes excess energy; and electroplating is not effective for dilute solutions.

Owing to the increasing environmental problems caused by the pollution of organic compounds and the increased environmental legislation restricting the use of conventional solvents [6], supercritical fluid (SCF) has become a promising alternative medium of more environmental soundness for replacement of conventional toxic organic solvents. Among the supercritical fluid mediums, carbon dioxide is the most favorable one due to its desirable properties, i.e. nontoxicity, non-flammability, good transport properties (density, viscosity, and diffusivity), low critical conditions (304.2 $\mathrm{K}$ and $7.38 \mathrm{MPa}$ ) and ready availability. In recent years, much effort has been on the research of supercritical fluid extraction (SFE), which has become an important technique in several fields of engineering such as food, chemical and environmental by using supercritical carbon dioxide $\left(\mathrm{SC} \mathrm{CO}_{2}\right)$. Extensive literature is available dealing with the solubility and extraction of organic compounds into $\mathrm{SC} \mathrm{CO}_{2}$ [7]. The Sherwood number has been correlated with Reynolds number and Schmidt number for the extraction of $\beta$-naphthol [8] and 1,2-dichlorobenzene [9] in packed beds. However, carbon dioxide is highly non-polar so that direct extraction of metal ions using $\mathrm{SC} \mathrm{CO}_{2}$ as solvent is inefficient, due to the requirement of charge neutralization and the weak solute-solvent interactions. Chelation with a suitable organic ligand can convert the charged metal species into neutral forms and thus a method of conventional solvent extraction of metal species has been developed [10,11]. In the early 1990s, many researchers started to employ
$\mathrm{SC} \mathrm{CO}_{2}$ with chelating agents for the extraction of metal species from various matrices such as aqueous solutions and soils [12-17]. Besides the environmental soundness, the $\mathrm{SC} \mathrm{CO}_{2}$ process has at least two advantages over the conventional solvent process, i.e. the ease of solvent recovery and the reduction in equipment size. The former can be achieved by a simple depressurization and the latter is due to an increased surface area of dispersed phase resulting from the lower surface tension of $\mathrm{SC} \mathrm{CO}_{2}$ than traditional organic solvents. However, high-pressure equipment is always expensive. The most expensive piece in an extraction process is probably the pump [6], which compresses the gas of carbon dioxide into the supercritical conditions. Besides, the operating cost will rise if the carbon dioxide goes through significant decompression/compression cycles.

The success of such an in situ chelation-SFE method for metal extraction from aqueous solution depends largely on the effectiveness of chelating agent, but also on other important parameters such as type of metal species and matrix, solubility and stability of the ligands and metal complexes, $\mathrm{pH}$, temperature, and pressure. Toews et al. [18] reported that when water is in equilibrium with $\mathrm{CO}_{2}$ under normal SFE conditions, the $\mathrm{pH}$ of water is less than 3.0 due to the formation and dissociation of carbonic acid. Therefore, acidic reagents are more effective than other type of reagents for metal extraction from a solution using $\mathrm{SC} \mathrm{CO}_{2}$ as solvent. Recent reports show that Cyanex 302 (diisooctyl-thiophosphinic acid) is an effective organic ligand for $\mathrm{SC} \mathrm{CO}_{2}$ extraction of most metals from a variety of matrices such as cellulose, sand, clay, wood, and soils $[15,16]$. Therefore, in this study, Cyanex 302 is used as the chelating agent with $\mathrm{SC} \mathrm{CO}_{2}$ as the solvent to extract metal ion from aqueous solutions.

The current study of chelation in supercritical fluids focuses on three potential applications including environmental treatment, metallurgical processing, and electronic materials/ceramics production. For example, deposing fine particulate metal-chelate complexes into electronic materials/ ceramics [19] for doping purpose [20], removal of toxic metals [12], and recovery of precious metals $[13,14]$. Many ions of metal species and various 
kinds of chelating agents have been studied [21]. Laintz et al. [12] first investigated the extraction of $\mathrm{Cu}$ (II) ion from an aqueous solution by chelation with LiFDDC (Lithium bis(trifluoroethyl) dithiocarbamate) using a dynamic extraction scheme. Nearly one hundred percent of the metal was removed from the aqueous sample after $1 / 2 \mathrm{~h}$ at a $\mathrm{CO}_{2}$ density of $370 \mathrm{~kg} / \mathrm{m}^{3}$ and a temperature of $308 \mathrm{~K}$. Lin et al. [13] studied the extractions of U(VI) and Th(IV) ions from synthetic aqueous solutions and U(VI) ion from mine waters at 333 $\mathrm{K}$ and 15.2 $\mathrm{MPa}$ using several different chelating agents. Lin and Wai [14] also studied the extractions of $\mathrm{La}(\mathrm{III}), \mathrm{Eu}(\mathrm{III})$, and Lu(III) ions. Smart et al. [15] investigated the extractions of $\mathrm{Cu}(\mathrm{II})$, $\mathrm{Pb}(\mathrm{II}), \mathrm{Zn}$ (II), and $\mathrm{Cd}(\mathrm{II})$ ions from cellulose, sand, clay, wood and soils with four commercially available organophosphorus chelating agents: Kelex 100, Cyanex 272, 301 and 302, and D2EHTPA (bis(2-ethylhexyl)monothiophosphoric acid). In these studies, the sizes of extraction cells

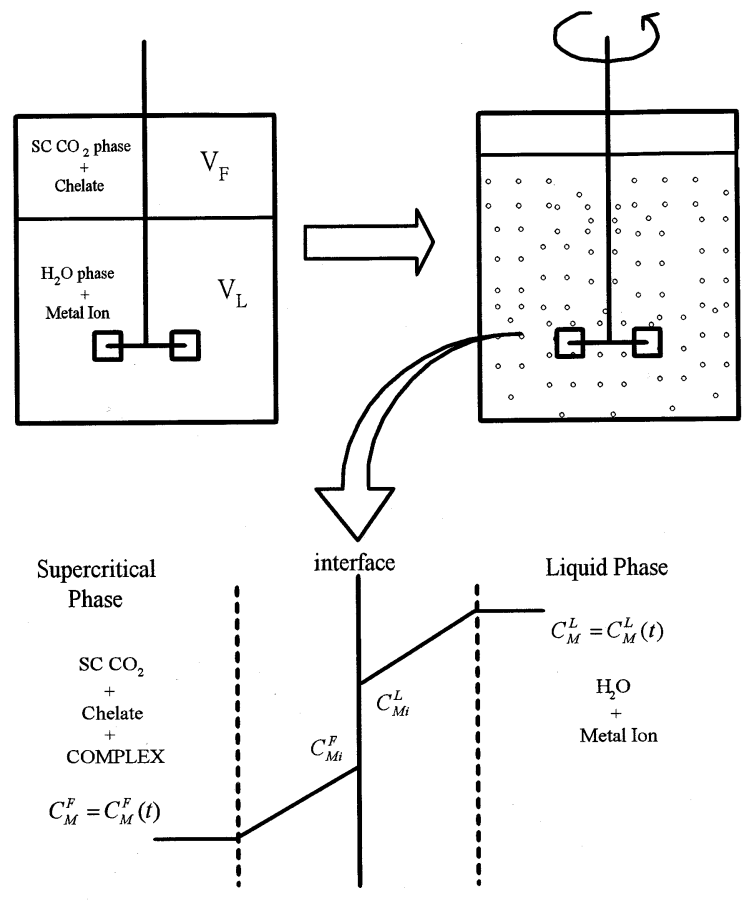

Fig. 1. Concentration profile of metal ion $\left(C_{\mathrm{M}}^{\mathrm{L}}\right)$ and metal complex $\left(C_{\mathrm{M}}^{\mathrm{F}}\right)$ in the neighborhood of a liquid/SC $\mathrm{CO}_{2}$, interface. are often smaller than $0.02 \mathrm{dm}^{3}$, and thus little kinetic information for equipment scale-up can be obtained. Recently, Murphy and Erkey [22] studied the extraction of copper(II) ion from aqueous solutions in a much larger vessel of $0.3-\mathrm{dm}^{3}$ and proposed a thermodynamic model that can accurately predicts the extraction efficiencies of copper(II) ion from aqueous solutions. However, kinetic information about the in situ chelationSFE technique was still lacking. From the viewpoint of process development, both the thermodynamic data and the kinetic information are important and required. The aim of this work is to study the kinetics of in situ chelation-extraction of zinc(II) ion from aqueous solutions in a $1.3-\mathrm{dm}^{3}$ stirred tank and to propose a simplified kinetic model for estimating the mass-transfer rate. Operating variables such as pressure and stirring rate that affects the extraction rate are investigated.

\section{Kinetic model for estimating mass-transfer coefficient}

The mass-transfer between phases for extraction of zinc(II) ion with the chelating agent in a stirred tank is shown in Fig. 1. By dispersing the $\mathrm{SC} \mathrm{CO}_{2}$ into the aqueous phase, coarse droplets of $\mathrm{SC} \mathrm{CO}_{2}$ in water are formed. Zinc(II) ion is transported to the liquid/SC $\mathrm{CO}_{2}$ interface and reacts with the chelating agent, which is Cyanex 302 in this study, to form a SC $\mathrm{CO}_{2}$-soluble zinc complex that then diffuses to the interior of the droplet.

$$
\mathrm{Zn}^{2+}+\underset{\text { (Cyanex 302) }}{2 \mathrm{C}_{16} \mathrm{H}_{35} \mathrm{OPS}} \underset{\text { (zinc complex) }}{\mathrm{Zn}\left(\mathrm{C}_{16} \mathrm{H}_{34} \mathrm{OPS}\right)_{2}}+2 \mathrm{H}^{+}
$$

Simultaneously, the hydrogen ion is released into the aqueous phase. After a long period of operation, the dispersion is allowed to settle and the closed system is in an equilibrium condition, which can be described by the equilibrium distribution coefficient, $m$ [12]:

$m=\frac{C_{\mathrm{M}}^{\mathrm{F}^{*}}}{C_{\mathrm{M}}^{\mathrm{L} *}}=\frac{C_{\mathrm{M}, \infty}^{\mathrm{F}}}{C_{\mathrm{M}, \infty}^{\mathrm{L}}}$ 
where, $C_{\mathrm{M}}^{\mathrm{L}}$ and $C_{\mathrm{M}}^{\mathrm{F}}$ are the concentrations of metal ion in the aqueous phase and of metal complex in $\mathrm{SC} \mathrm{CO}_{2}$ phase, respectively. The superscript $(*)$ means the equilibrium condition and the subscript $(\infty)$ means the time to infinity. Since the concentration of metal species in the wastewater is often below $2-\mathrm{kg} / \mathrm{m}^{3}$ (2000 ppm) [1], which corresponds to the mole fraction of about $10^{-4}$, the equilibrium distribution coefficient is often assumed constant at low concentration when the temperature and pressure are fixed. This assumption is applied to the derivation of kinetic model in this study to estimate the effective mass-transfer coefficient. The kinetics of zinc extraction can be interpreted using film theory for two-phase reaction [23]. In our system the following masstransfer resistances exist: the mass-transfer resistance in the liquid film, the resistance of the chemical reaction between the zinc(II) ion and the chelating agent, and the mass-transfer resistance in the $\mathrm{SC} \mathrm{CO}_{2}$ film. The characteristics of the three resistances are discussed below.

For a solute crossing a mass-transfer resistance film, the transfer time can be approximately estimated by the following equation: [24]

transfer time $=\frac{(\text { film thickness })^{2}}{(\text { diffusion coefficient })}$

The film thickness is about $0.5 \times 10^{-4} \mathrm{~m}$ [25] and the diffusion coefficient is around $10^{-9} \mathrm{~m}^{2} / \mathrm{s}$ for most of mass-transfer cases in liquid phase. The estimated transfer time for a solute crossing the aqueous mass-transfer resistance film is about 2.5 s. On the other hand, according to Taylor and Krishna [25], the film thickness is assumed to be $10^{-4} \mathrm{~m}$ for a $\mathrm{SC} \mathrm{CO}_{2}$ film because of the gas-like and liquid-like properties of $\mathrm{SC} \mathrm{CO}_{2}$. The diffusion coefficient of solute in supercritical fluid is around $10^{-8} \mathrm{~m}^{2} / \mathrm{s}$ [26] and thus the estimated transfer time for a solute crossing a $\mathrm{SC} \mathrm{CO}_{2}$ film is about $1 \mathrm{~s}$. In comparison with the shortest extraction time of about 500-s required to reach equilibrium state in this study, the total estimated transfer time of $3.5 \mathrm{~s}$ is very short. Therefore, the mass-transfer behaviors within both films of liquid and $\mathrm{SC} \mathrm{CO}_{2}$ closely approach the linear driving force model (LDF model) of film theory, which assumes the concentration profile within the film is linear. In fact, the LDF model of film theory has been used to estimate the mass-transfer rate across the liquid film for studies of mercury extraction in a stirred tank under atmosphere $[27,28]$. In order to estimate the mass-transfer rate of the in situ chelation-SFE process, a simplified LDF model is proposed here.

For the $\mathrm{SC} \mathrm{CO}_{2}$ extraction of zinc(II) ion with Cyanex 302 as the chelating agent, some facts exist: (1) The chelation reaction is fast and the kinetics of extraction were not limited by the rate of complex formation on the time scale of minutes [15]; (2) Zinc(II) ion is insoluble in the $\mathrm{SC} \mathrm{CO}_{2}$ phase; (3) The oily chelating agent, Cyanex 302, is hydrophobic and is sparingly soluble in the aqueous phase; (4) The transport properties of solutes in the $\mathrm{SC} \mathrm{CO}_{2}$ phase is much better than that in aqueous phase as far as the transport rate is concerned. For example, the diffusivities and viscosities of solutes in $\mathrm{SC} \mathrm{CO}_{2}$ phase are about ten times and a tenth of that in normal liquids, respectively [26,29]. The first three facts suggest the chelation reaction occur mostly at the liquid/ $\mathrm{SC} \mathrm{CO}_{2}$ interface. The fourth fact suggests the concentration profile be flat in the small $\mathrm{SC} \mathrm{CO}_{2}$ droplet. Therefore, the $\mathrm{SC} \mathrm{CO}_{2}$ extraction of zinc(II) ion with Cyanex 302 as the chelating agent is a mass-transfer limited process; the chelation reaction occurs only at the liquid/SC $\mathrm{CO}_{2}$ interface, where zinc species are in reaction equilibrium with Cyanex 302 as Eq. (1). The Cyanex 302 is in larger excess in comparison with the small amount of zinc species for this study and thus the concentration effect of Cyanex 302 is assumed negligible. Furthermore, the hydrogen ion concentration is assumed to remain constant in aqueous phase because the diffusivity of hydrogen ion is high and the amount of hydrogen ion generated in aqueous solution is small under a $\mathrm{pH}$ of 2.9 in equilibrium with $\mathrm{SC} \mathrm{CO}_{2}$ [18]. Based on these assumptions, the in situ chelation-SFE process can be regarded as a simple extraction of zinc species without considering the chemical reaction. The molar flux per unit surface area $\left(N_{\mathrm{M}}\right)$ expressed in the form of an overall LDF model is as follows:

$N_{\mathrm{M}}=K_{\mathrm{F}}\left(C_{\mathrm{M}}^{\mathrm{F} *}-C_{\mathrm{M}}^{\mathrm{F}}\right)$ 


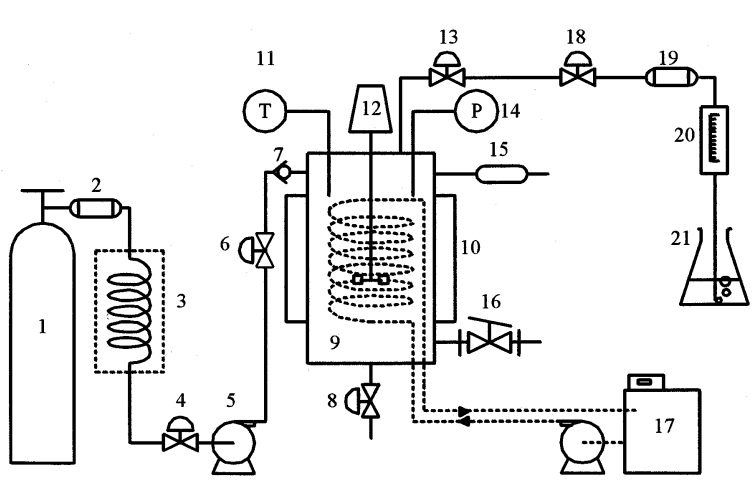

Fig. 2. Experimental apparatus: $1, \mathrm{CO}_{2}$ vessel; 2, filter; 3, cooler; 4 , ball valve; 5 , mini pump; 6 , ball valve; 7 , check valve; 8 , feeding valve; 9, stirred tank; 10, windows; 11, thermometer; 12, agitator; 13, ball valve; 14, pressure gauge; 15, rupture disc; 16, sampling valve; 17 , water bath; 18 , metering valve; 19 , collector; 20 , flow meter; 21 , water vessel.

where, $K_{\mathrm{F}}$ is the overall mass-transfer coefficient, and $C_{\mathrm{M}}^{\mathrm{F}^{*}}$ is the concentration of $\mathrm{SC} \mathrm{CO}_{2}$ phase in equilibrium with aqueous phase of concentration $C_{\mathrm{M}}^{\mathrm{L}}$. The value of $C_{\mathrm{M}}^{\mathrm{F} *}$ is equal to the product of the equilibrium distribution coefficient $(m)$ and the concentration of aqueous phase $\left(C_{\mathrm{M}}^{\mathrm{L}}\right)$. Therefore, the mass balance equations, describing masstransfer in a batch stirred tank, are written as follows:In the aqueous phase

$\frac{\mathrm{d} C_{\mathrm{M}}^{\mathrm{L}}}{\mathrm{d} t}=-K_{\mathrm{F}} a\left(m C_{\mathrm{M}}^{\mathrm{L}}-C_{\mathrm{M}}^{\mathrm{F}}\right)$

and in the $\mathrm{SC} \mathrm{CO}_{2}$ phase

$V_{\mathrm{F}} \frac{\mathrm{d} C_{\mathrm{M}}^{\mathrm{F}}}{\mathrm{d} t}=V_{\mathrm{L}} K_{\mathrm{F}} a\left(C_{\mathrm{M}}^{\mathrm{L}}-C_{\mathrm{M}}^{\mathrm{F}}\right)$

where, $a$ is the surface area per unit volume of aqueous phase, $V_{\mathrm{F}}$ and $V_{\mathrm{L}}$ are the volume of $\mathrm{SC}$ $\mathrm{CO}_{2}$ phase and aqueous phase, respectively. The following conditions applies:

at $t=0, \quad C_{\mathrm{M}}^{\mathrm{F}}=C_{\mathrm{M}, 0}^{\mathrm{F}}, \quad C_{\mathrm{M}}^{\mathrm{L}}=C_{\mathrm{M}, 0}^{\mathrm{L}}$

at $t=\infty, \quad C_{\mathrm{M}}^{\mathrm{L}}=C_{\mathrm{M}, \infty}^{\mathrm{L}}$

The Laplace transform technique can solve the above set of equations and the result is:

$\ln \left(\frac{C_{\mathrm{M}}^{\mathrm{L}}-C_{\mathrm{M}, \infty}^{\mathrm{L}}}{C_{\mathrm{M}, 0}^{\mathrm{L}}-C_{\mathrm{M}, \infty}^{\mathrm{L}}}\right)=-\alpha t$

where,
$\alpha=K_{\mathrm{F}} a\left(\frac{V_{\mathrm{L}}}{V_{\mathrm{F}}}+m\right)$

The mass balance equation of metal species at the infinite time is as follow:

$V_{\mathrm{F}} C_{\mathrm{M}, \infty}^{\mathrm{L}}=V_{L}\left(C_{\mathrm{M}, \text { load }}^{\mathrm{L}}-C_{\mathrm{M}, \infty}^{\mathrm{L}}\right)$

where, the subscript, load, means the initial loading of metal species in the stirred tank. Combine Eq. (1) and Eq. (11), and then the equilibrium distribution coefficient can be calculated by the following equation,

$m=\frac{V_{\mathrm{L}}}{V_{\mathrm{F}}}\left(\frac{C_{\mathrm{M}, \text { load }}^{\mathrm{L}}}{C_{\mathrm{M}, \infty}^{\mathrm{L}, \infty}}-1\right)$

Hence, by plotting the dimensionless concentration $\left(\left(C_{\mathrm{M}}^{\mathrm{L}}-C_{\mathrm{M}, \infty}^{\mathrm{L}}\right) /\left(C_{\mathrm{M}, 0}^{\mathrm{L}}-C_{\mathrm{M}, \infty}^{\mathrm{L}}\right)\right)$ versus time $(t)$ on a semi-log plot, a linear equation that passes through the origin is obtained, then, the effective mass-transfer coefficient $K_{\mathrm{F}} a$ is evaluated from the slope $\alpha$. The dimension of the effective mass-transfer coefficient is time ${ }^{-1}$, which is not affected by the units used for volume and concentration.

\section{Experimental section}

Experiments were performed in a $1.3-\mathrm{dm}^{3}$ batch stirred tank. The inner diameter is $7.6 \mathrm{~cm}$ and the inner height is $28.5 \mathrm{~cm}$. The schematic diagram of the experimental apparatus is shown in Fig. 2. The system is mainly composed of three parts: (1) a feeding system, (2) a pressurized reaction-extraction vessel, and (3) a pressure releasing system. The feeding system is made up of a $\mathrm{CO}_{2}$ cylinder loaded with liquid $\mathrm{CO}_{2}$, a filter for filtering out the fine particles, a cooler for preventing liquid $\mathrm{CO}_{2}$ from vaporization, and a piston pump (LDC analytical mini pump) for feeding liquid carbon dioxide. The pressurized reaction-extraction vessel is a $1.3-\mathrm{dm}^{3}$ stirred tank that is equipped with a mechanical agitator for mixing, a heat transfer coil for maintaining a constant temperature, a sampling valve for drawing the liquid samples, a feeding needle valve for loading the aqueous solution, a pressure gauge, a rupture disc (NUPRO R3A-G relief valve), a thermometer, and two pairs of viewing windows. The impeller is a tur- 
bine impeller with a diameter of $2.8 \mathrm{~cm}$ and the maximum stirring rate of the mechanical agitator is $20 \mathrm{~s}^{-1}$. The water flowing inside the heat transfer coil is supplied from a constant temperature bath. The sampling valve is a switching valve (Rheodyne model 7010), which allows a slow flow for maintaining a stable pressure. The pressure releasing system consists of a metering valve for controlling the rate of depressurization, a collector for collecting the entrained chemicals, a flow meter for measuring the amount of $\mathrm{CO}_{2}$ used, and a trap for absorbing the organic residue in the effluent. The metering valve is heated to prevent clogging due to the solidifying of carbon dioxide.

At the beginning of an experiment, $0.8 \mathrm{dm}^{3}$ of $150-\mathrm{mg} / \mathrm{l}\left(2.29 \mathrm{~mol} / \mathrm{m}^{3}\right)$ aqueous solution of $\mathrm{Zn}\left(\mathrm{NO}_{3}\right)_{2}$ was preheated to $313 \mathrm{~K}$ and then fed into the stirred tank, which is maintained at 315 $\mathrm{K}$, through the feeding needle valve at its bottom. And thus the volume holdup of $\mathrm{SC} \mathrm{CO}_{2}$ is about $38 \%$. Besides, a $4-\mathrm{cm}^{3}$ amount of Cyanex 302 of Fluka technical grade (diisooctyl-thiophosphinic acid, Fluka product No. 38 224, $\approx 85 \%$ pure, density: $0.93 \mathrm{~g} / \mathrm{cm}^{3}$ ) was injected into the stirred tank through a top hole by a syringe. Cyanex 302 was floating on the surface of aqueous solution because it is hydrophobic. When the experiment was in progress, a stainless plug was used to seal this top hole. Because of no available solubility data of Cyanex 302 at the experimental temperature of $313.15 \mathrm{~K}$, this amount of Cyanex 302 was determined by trial and error method to insure that no third phase present in the reactor. The initial try of amount of Cyanex 302 is based on its solubility of $8 \mathrm{~g} / \mathrm{dm}^{3}$ at $11.2 \mathrm{MPa}$ and $333.15 \mathrm{~K}$ [15,21]. The test runs show that no third phase present in the reactor when a $4-\mathrm{cm}^{3}$ amount of Cyanex 302 was introduced. The amount of Cyanex 302 used was in excess, about 13 times of that of zinc(II) ion on a molar basis. Therefore, the concentration change of Cyanex 302 was small and thus the concentration effect of Cyanex 302 is assumed negligible in the kinetic study. These chemicals were used as received without further purification.

The liquid carbon dioxide was then delivered to the stirred tank until the desired pressure was reached, which varied from run to run between
8.3 and 13.8 $\mathrm{MPa}$. During the transient period to reach the system pressure, the chelating agent started to contact with the aqueous solution of zinc(II) ion and the chelation reaction was in progress, however, the concentration distribution was not homogeneous in the stirred tank. Thus, the concentration change of zinc(II) ion in the aqueous solution is not suitable for kinetic analysis. In this transient period, the system was kept still without agitation in order to reduce the extent of reaction between zinc(II) ion and chelating agent. When the desired pressure was reached, it was found that the $4.0 \mathrm{~cm}^{3}$ of Cyanex $302 \mathrm{com}$ pletely dissolved in the $\mathrm{SC} \mathrm{CO}_{2}$. After that valve 6 was closed so that the stirred tank became a batch system. Then, the agitator was started to mix the solution. The stirring rate varied from 7.2 to 17.7 $\mathrm{s}^{-1}$ for different runs. After $30 \mathrm{~s}$ of stirring, the solution was well mixed and the system pressure and temperature became steady. Through the viewing windows, a well-dispersed solution of fine $\mathrm{SC} \mathrm{CO}_{2}$ droplets in water was observed inside the extractor. At this moment of steady condition, we switched the timer on, and opened the sampling valve 8 to draw $1 \mathrm{~cm}^{3}$ of liquid sample for the first analysis. Then, the sampling interval was $120 \mathrm{~s}$ in the first $1800-\mathrm{s}$ period and then changed to $900 \mathrm{~s}$ after that. The total experimental period was about $7200 \mathrm{~s}$, at which the zinc(II) ion concentration had leveled off for all experimental runs. During this experimental period, no third phase of metal complex was found in the stirred tank. At the end of an experiment, the system was depressurized through the metering valve 18. All the samples were analyzed for the zinc(II) ion concentration by an inductively coupled plasma (ICP) spectrometer.

\section{Results and discussion}

In this work, the initial concentration of zinc(II) ion and the mole ratio of zinc(II) ion/ chelating agent are kept constant to investigate the effects of pressure and agitation rate. A typical result of the in situ chelation-SFE process in a batch stirred tank is shown in Fig. 3. It can be seen that the concentration profile of zinc(II) ion 


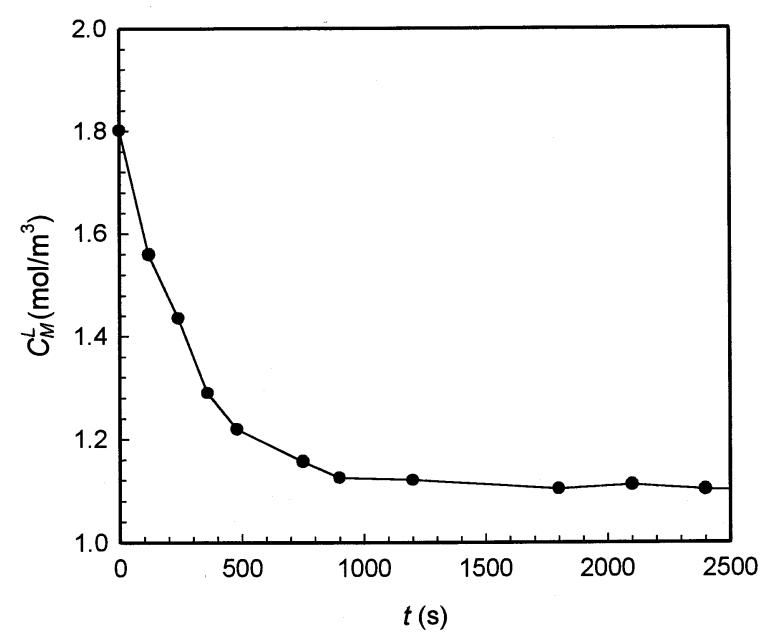

Fig. 3. A plot of zinc(II) ion concentration $\left(C_{\mathrm{M}}^{\mathrm{L}}\right)$ in aqueous solution against operating time $(t)$ (temperature, $313 \mathrm{~K}$; pressure, 8.3 $\mathrm{MPa}$; stirring rate, $13.2 \mathrm{~s}^{-1}$ ).

decays sharply at the initial period and then decreases smoothly to a steady value, at which the condition is approaching equilibrium state. Because there is a transient period at the initial stage of operation as stated in Section 3, the starting concentration of zinc(II) ion is not the initial concentration of $150 \mathrm{mg} / 1\left(2.29 \mathrm{~mol} / \mathrm{m}^{3}\right)$. Instead, it is the concentration when the system pressure becomes steady at $8.3 \mathrm{MPa}$. According to Eq. (9), the corresponding semi-log plot of dimensionless concentration versus time is illustrated in Fig. 4. It behaves just like the model description: a straight line passes through the origin. The values of correlation coefficients for all experiments are between 0.986 and 0.998 . Thus the simplified model can be used to estimate the effective masstransfer coefficient $\left(K_{\mathrm{F}} a\right)$. The calculated masstransfer coefficients are listed in Table 1 . The effective mass-transfer coefficients range from 0.2 to $2.6 \times 10^{-3} \mathrm{~s}^{-1}$. These values are lower than the effective mass-transfer coefficients $\left(K_{\mathrm{F}} a\right)$ determined for the stirred tank at atmospheric pressure [30] and the packed bed at supercritical conditions [8,9]. A comparison of data is summarized in Table 2. Gollakota and Guin [30] studied the mass-transfer in a batch stirred autoclave with turbine impeller at atmospheric pressure. The diameter is $3.0 \mathrm{~cm}$ for the impeller and $4.5 \mathrm{~cm}$ for the vessel. The volume holdup of gas is $50 \%$. When the impeller is stirred at the range of $12.9-$ $17.5 \mathrm{~s}^{-1}$, they obtain a small interfacial area of $17.9-42.3 \mathrm{~m}^{-1}$, which is quite smaller than that in a packed bed reported by Puiggené et al. [9]. The vessel diameter, the impeller diameter, and the volume holdup of gas in the extractor used by Gollakota and Guin are somewhat close to the

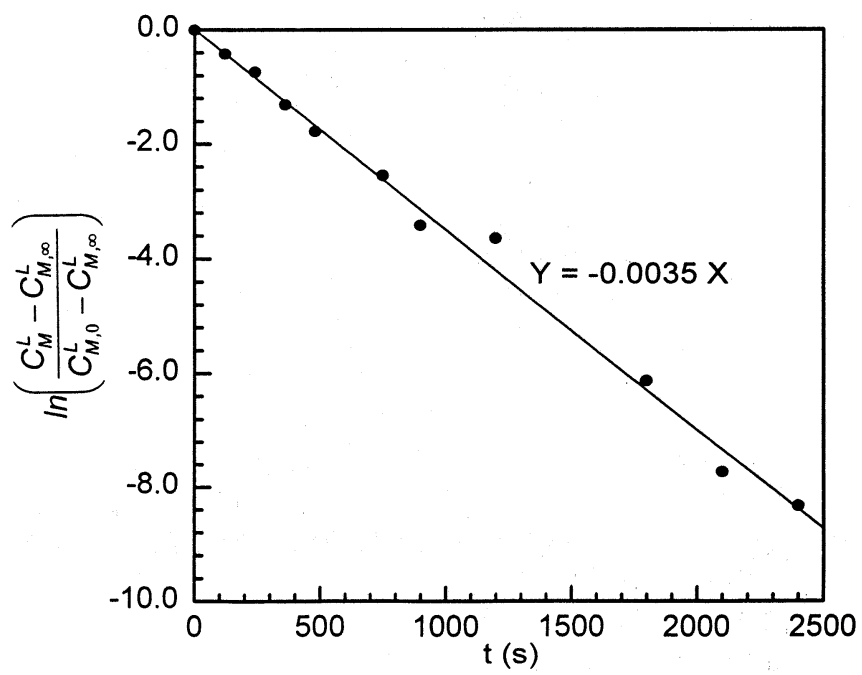

Fig. 4. A plot of Eq. (9), $\log \left(C_{\mathrm{M}}^{\mathrm{L}}-C_{\mathrm{M}, \infty}^{\mathrm{L}} / C_{\mathrm{M}, 0}^{\mathrm{L}}-C_{\mathrm{M}, \infty}^{\mathrm{L}}\right)$ against operating time $(t)$ (temperature, $313 \mathrm{~K}$; pressure, $8.3 \mathrm{MPa}$; stirring rate, $\left.13.2 \mathrm{~s}^{-1}\right)$. 
Table 1

Effective mass-transfer coefficients for various operating conditions

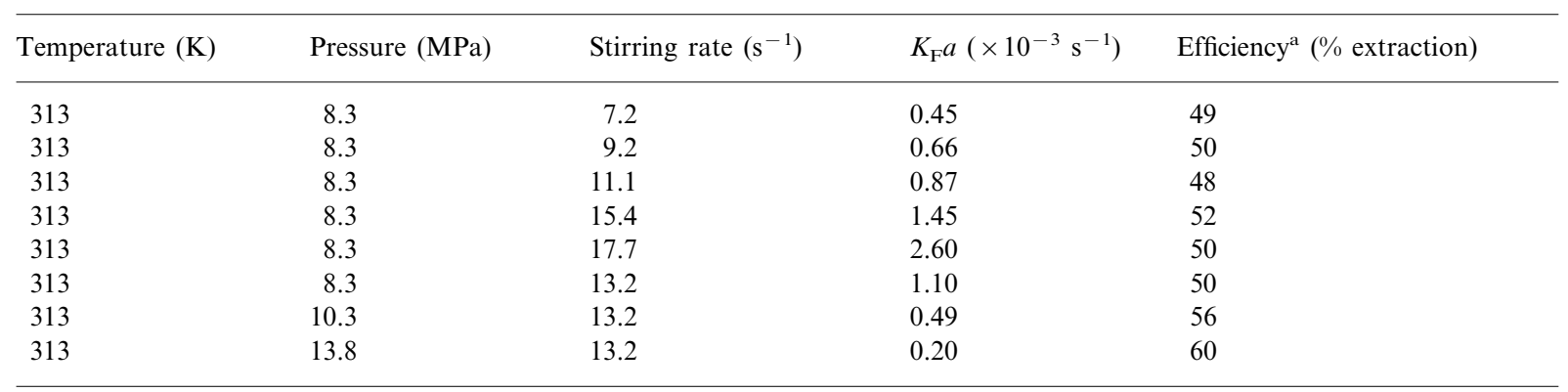

${ }^{a}$ The efficiency is expressed as $\%$ extraction at the end of a $2 \mathrm{~h}$ experiment.

Table 2

Mass-transfer coefficient for different systems

\begin{tabular}{lllll}
\hline Device & System & Experimental results & Interfacial area & Reference \\
\hline Stirred tank & $\mathrm{SCF} /$ liquid & $K_{\mathrm{F}} a=0.2-2.6 \times 10^{-3} \mathrm{~s}^{-1}$, when $N=7.2-17.7$ & - & This work \\
& & $\mathrm{s}^{-1}$ & $a=1214 \mathrm{~m}^{-1}$ & Puiggene et al. [9] \\
Packed bed & $\mathrm{SCF} /$ liquid & $K_{\mathrm{F}} a=1.7-24 \times 10^{-3} \mathrm{~s}^{-1}$ & - & Tan et al. [8] \\
Packed bed & $\mathrm{SCF} /$ solid & $K_{\mathrm{F}} a=3.0-40 \times 10^{-3} \mathrm{~s}^{-1}$ & Gollakote and Guin [30] \\
Stirred tank & Gas/liquid & $k_{\mathrm{L}} a=4.9-19.8 \times 10^{-3} \mathrm{~s}^{-1}$, when $N=12.9-17.5$ & $a=17.9-42.3$ & $\mathrm{~m}^{-1}$ \\
& & $\mathrm{~s}^{-1}$ & & \\
\hline
\end{tabular}

experimental system used in this study. Therefore, the low $K_{\mathrm{F}} a$ obtained in this study is probably due to a low interfacial surface area, $a$, associated with a batch stirred tank.

\subsection{Effect of stirring rate on mass-transfer coefficient}

When the system is operated at $8.3 \mathrm{MPa}$ and $313 \mathrm{~K}$, the concentration profiles of zinc ion during a extraction process at various stirring rates are plotted in Fig. 5. In order to see clearly the concentration change at the initial period, the time scale is plotted to $1800 \mathrm{~s}$ only. Because the transient period to reach the system pressure varies from run to run, the starting concentration in the figure also varies. However, there is a trend that indicates that the higher the stirring rate of agitator, the faster the removal rate of zinc(II) ion. Using Eq. (9), the calculated mass-transfer coefficients at various stirring rates are listed in the first six runs of Table 1 and are plotted against stirring rate as shown in Fig. 6. The calculated mass-transfer coefficient shows a 5.8time difference between the stirring rates of 17.7 and $7.2 \mathrm{~s}^{-1}$. From Fig. 6, it can be seen that a higher stirring rate gives a larger effective mass-

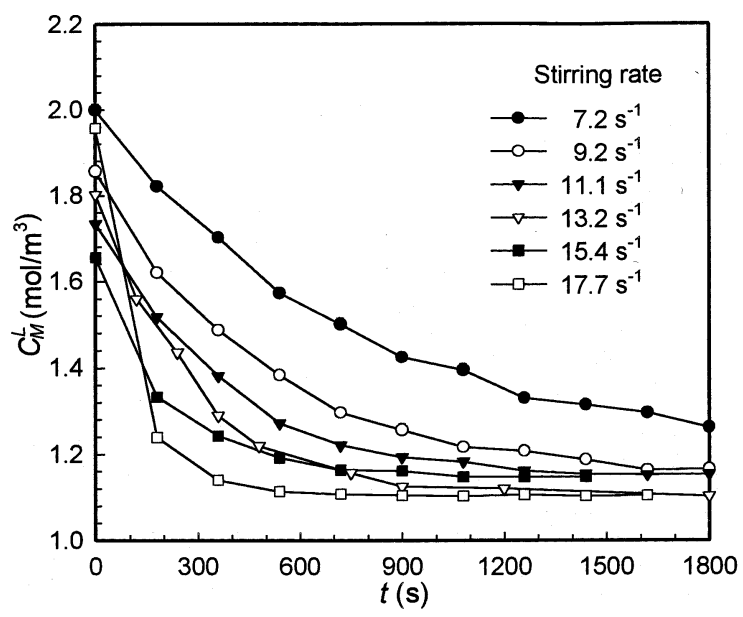

Fig. 5. Zinc(II) ion concentration $\left(C_{\mathrm{M}}^{\mathrm{L}}\right)$ in aqueous solution against operating time $(t)$ at various stirring rate (temperature, $313 \mathrm{~K}$; pressure: $8.3 \mathrm{MPa}$ ). 


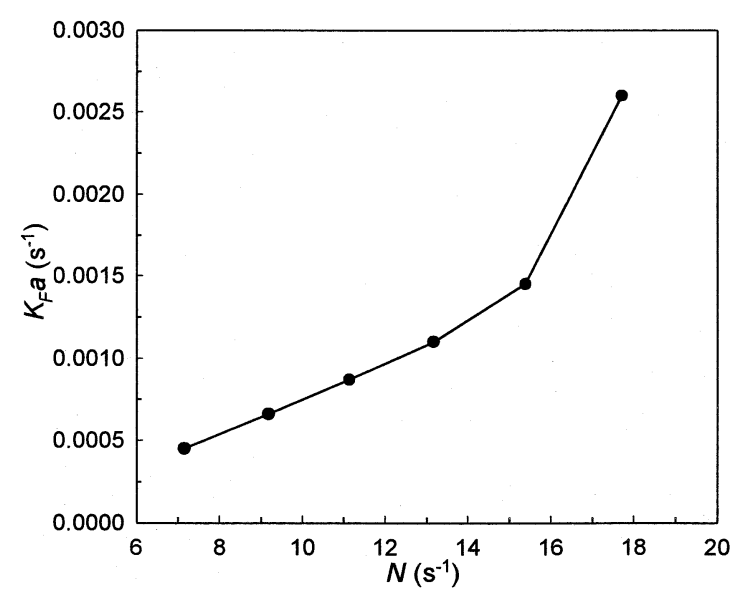

Fig. 6. Effect of stirring rate $(N)$ on effective mass-transfer coefficient $\left(K_{\mathrm{F}} a\right)$ (temperature, $313 \mathrm{~K}$; pressure, $8.3 \mathrm{MPa}$; operation time, $7200 \mathrm{~s})$.

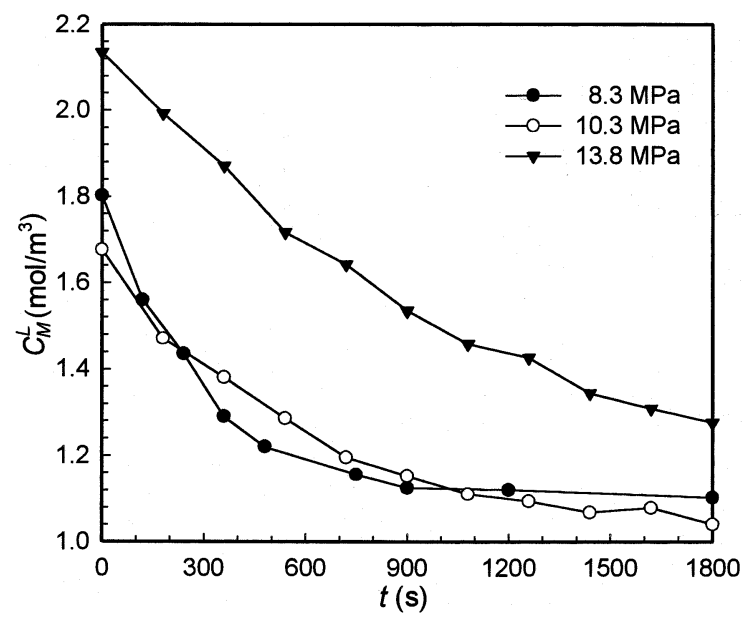

Fig. 7. Zinc(II) ion concentration $\left(C_{\mathrm{M}}^{\mathrm{L}}\right)$ in aqueous solution against operating time $(t)$ at various pressures (temperature, $313 \mathrm{~K}$; stirring rate, $13.2 \mathrm{~s}^{-1}$ ).

transfer coefficient, which consists with the results in Fig. 5, i.e. the higher the decreasing rate of zinc(II) ion, the larger the effective mass-transfer coefficient. This is because increased stirring rate produces much more number of bubble [31] and thins the mass-transfer resistance film. The more bubbles produce more mass-transfer surface $(a)$. The thinned mass-transfer film enhances the masstransfer rate and thus the overall mass-transfer coefficient $\left(K_{\mathrm{F}}\right)$. Therefore, the effective mass- transfer coefficient $\left(K_{\mathrm{F}} a\right)$ increases with an increase in the stirring rate of agitator. The steep increase in the effective mass-transfer coefficient at the highest stirring rate of $17.2 \mathrm{~s}^{-1}$ in Fig. 6 may be due to a tremendous increase in surface area, resulting from the formation of a larger number of small bubbles as observed through the viewing windows.

\subsection{Effect of pressure on mass-transfer coefficient}

In order to see the pressure effect on the zinc extraction, the stirring rate of agitator was fixed at $13.2 \mathrm{~s}^{-1}$ and the temperature was operated at $313 \mathrm{~K}$. The concentration profiles of zinc ion extraction at 8.3,10.3, and 13.8 $\mathrm{MPa}$ are plotted in Fig. 7. Again, the time scale is only plotted to $1800 \mathrm{~s}$ to see clearly the concentration change at the early stage of extraction. It can be seen that a higher pressure gives a flatter concentration profile, which means that the increased pressure retards the mass-transfer rate for zinc ion extraction from aqueous solutions. The calculated effective mass-transfer coefficients $K_{\mathrm{F}} a$ are listed at the last three runs of Table 1, which shows the same trend shown in Fig. 7, i.e. the higher the pressure, the smaller the effective mass-transfer coefficient. In the literature, similar results for organic extraction in packed bed using $\mathrm{SC} \mathrm{CO}_{2}$ as solvent have been reported [9,32]. Usually the mass-transfer coefficient can be predicted from the Frösslingtype equation:

$$
\mathrm{Sh}=A \mathrm{Re}^{b} \mathrm{Sc}^{c}
$$

where $A$ is a constant and $c$ usually has a value of $1 / 3[8,9,33-35]$. The value of $b$ depends on the type of equipment and system, for example, Tan and his coworkers [8] and Puiggené et al. [9] reported a value of about 0.80 for $b$ in packed beds undergoing supercritical fluid extraction, on the other hand, most of the theories predict a one-half power on Reynolds number [24]. For mass-transfer across liquid-liquid interface in a stirred system, the Sherwood number is usually defined as $k d / D$ and Reynolds number as $N d^{2} \rho / \mu$, where $N$ and $d$ are the stirring rate and the impeller diameter, respectively [34-36]. If the con- 
stancy of the product of density $\rho$ and diffusion coefficient $D$ in supercritical fluids under normal SFE conditions can be assumed [26], the following relation is obtained from Eq. (13).

$k \propto N^{b} d^{2 b-1} D^{1-b} \mu^{1 / 3-b}$

In this system $D$ is the diffusion coefficient of zinc(II) ion in liquid and $\mu$ is the viscosity of liquid solution because the liquid-film control is assumed. Since $b$ falls between 0.5 and 0.8 , we have $1-b>0$ and $1 / 3-b<0$. Under a constant stirring rate, the mass-transfer coefficient is a function of diffusion coefficient and viscosity. For liquid system, the diffusion coefficient is inversely proportional to the viscosity according to the Stokes-Einstein equation [37]. The increased pressure results in a higher viscosity [38] and thus a small diffusion coefficient. Therefore, it can be seen from Eq. (14) that a high pressure gives a small mass-transfer coefficient $(k)$. If the masstransfer resistance on the $\mathrm{SC} \mathrm{CO}_{2}$ side is considered, a similar trend is predicted because Paulaitis et al. [26] reported that the viscosity of $\mathrm{SC} \mathrm{CO}_{2}$ increases with pressure and the diffusion coefficient of solute in $\mathrm{SC} \mathrm{CO}_{2}$ decreases with pressure. On the other hand, an increase in pressure ranging from 6.8 to $16.0 \mathrm{MPa}$ results in a smaller surface tension of $\mathrm{SC} \mathrm{CO}_{2}$ [39] and thus the smaller $\mathrm{SC} \mathrm{CO}_{2}$ droplet size, which results in a larger surface area $(a)$ of dispersed phase for extraction. Therefore, the effect of pressure on the effective mass-transfer coefficient, which is the product of mass-transfer coefficient and surface area of dispersed phase, can go either way. The obtained values of $K_{\mathrm{F}} a$ listed in Table 1 show a five-time difference between the highest and the lowest pressure. Apparently, the effect of the reduction in mass-transfer coefficient $\left(K_{\mathrm{F}}\right)$ exceeds that of the increase in surface area $(a)$ when the pressure increases.

\subsection{Extraction efficiency of $Z n(I I)$ ion}

The extraction efficiency listed in Table 1 is expressed as \% extraction at the end of a 2-h experiment. The $\%$ extraction is defined as follows:
$\%$ extraction

$$
\begin{aligned}
= & \frac{\text { metal ion loaded }- \text { metal ion remaing }}{\text { metal ion loaded }} \\
& \times 100 \%
\end{aligned}
$$

The change in stirring rate of agitator shows no effect on the extraction efficiency from the first five experimental runs. This is because the extraction efficiency depends on the equilibrium state. The change of stirring rate can only change the time required to reach the equilibrium state but can not shift the equilibrium state. On the other hand, as shown at the last three experimental runs in Table 1, the extraction efficiency rises from 50 to $60 \%$ with the increase of pressure from 8.3 to 13.8 $\mathrm{MPa}$ when the stirring rate is operated at $13.2 \mathrm{~s}^{-1}$. This is because the system has reached equilibrium condition and the solubility of zinc complex is higher at higher pressure in supercritical $\mathrm{CO}_{2}$ [15]. Similar results of pressure effect on the extraction efficiency are found in the extractions of different metals using various chelating agents $[12,15,16,22]$. The change in extraction efficiency with pressure is not great as compared with the change in effective mass-transfer coefficient, which shows a five-time difference between 8.3 and $13.8 \mathrm{MPa}$. Therefore, extraction rate will be favored at low pressure. Besides, as shown in Fig. 5 and Fig. 7, the concentration of zinc ion in the treated solutions is above $1.0 \mathrm{~mol} / \mathrm{m}^{3}$, corresponding to $65 \mathrm{mg} / \mathrm{l}$, which is too high for the environmental acceptance [40]. Therefore, the extraction efficiency is too low by using a batch operation. A process of multistage or continuous operation should be developed.

\section{Conclusions}

Extraction of zinc(II) ion from aqueous solution by using an in situ chelation-SFE technique with Cyanex 302 as the chelating agent was studied in a $1.3-\mathrm{dm}^{3}$ batch stirred tank. The extraction efficiency, which is expressed as \% extraction at the end of 2-h operation, varies from 50 to $60 \%$ when the pressure varies from 8.3 to $13.8 \mathrm{MPa}$. The stirring rate has no effect on the extraction 
efficiency. Under a few assumptions, the in situ chelation-SFE process is regarded as a simple extraction process without considering chemical reaction and a simplified model based on the film theory is developed to estimate the effective masstransfer coefficient. The calculated effective masstransfer coefficient $\left(K_{\mathrm{F}} a\right)$ is lower than those reported in the literature. The results show that the effective mass-transfer coefficient increases with an increase in stirring rate, but decreases with pressure. Besides, the effective mass-transfer coefficient is greatly affected by the stirring rate and shows a 5.8-time difference between 7.2 and $17.7 \mathrm{~s}^{-1}$. As a result, the pressure effects on the extraction efficiency and on the mass-transfer rate are reversed and thus there exists an optimum pressure for practical purpose. However, the lower pressure in the range studied is favored, because the extraction efficiency is affected to a less extent. As far as process design and equipment scale-up are concerned, much more effort should be stressed on establishing a general correlation for the estimation of mass-transfer coefficient. Future work will be on the development of a continuous flow system, which is the common type of a commercial process.

\section{Acknowledgements}

The authors gratefully acknowledge the financial support of the National Science Council of the Republic of China.

\section{References}

[1] G.Y. Shu, J.C. Liu, Content and fractionation of heavy metals in soils of two contaminated sites in Taiwan, Environ. Prog. 13 (1994) 89.

[2] Y. Ku, R.W. Peters, The effect of weak chelating agents on the removal of heavy metals by precipitation processes, Environ. Prog. 5 (1986) 147.

[3] M. Schöller, J.C. van Dijk, D. Wilms, Fluidized bed pellet reactor to recover metals or anions, Metal Finishing 89 (1991) 46.

[4] C.Y. Tai, W.C. Chien, C.Y. Chen, Crystal growth kinetics of calcite in a dense fluidized-bed crystallizer, AIChE J. 45 (1999) 1605.
[5] R.W. Peters, Y. Ku, D. Bhattacharyya, Evaluation of recent treatment techniques for removal of heavy metals from industrial wastewater, AIChE Symp. Ser. 81 (1985) 165.

[6] C.L. Phelps, N.G. Smart, C.M. Wai, Past, present, and possible future applications of supercritical fluid extraction technology, J. Chem. Educ. 73 (1996) 1163.

[7] P.C. Chen, M. Tang, Y.P. Chen, Calculations of the solubilities of solids in supercritical fluids using the PengRobinson equation of state and a modified mixing model, Ind. Eng. Chem. Res. 34 (1995) 332.

[8] C.S. Tan, S.K. Liang, D.C. Liou, Fluid-solid mass-transfer in a supercritical fluid extractor, Chem. Eng. J. 38 (1988) 17.

[9] J. Puiggené, M.A. Larrayoz, F. Recasens, Free lquid-tosupercritical fluid mass-transfer in packed beds, Chem. Eng. Sci. 52 (1997) 195.

[10] B.K. Tait, The extraction of some base metal ions by Cyanex 301, Cyanex 302 and their binary extractant mixtures with Aliquat 336, Solvent Extr. Ion Exch. 10 (1992) 799.

[11] M. Cox, Solvent extraction in hydrometallurgy, in: J. Rydberg, C. Musikas, G.R. Choppin (Eds.), Principles and Practices of Solvent Extraction, Marcel Dekker, New York, 1992, p. 357.

[12] K.E. Laintz, C.M. Wai, C.R. Yonker, R.D. Smith, Extraction of metal ions from liquid and solid materials by supercritical carbon dioxide, Anal. Chem. 64 (1992) 2875.

[13] Y. Lin, C.M. Wai, F.M. Jean, R.D. Brauer, Supercritical fluid extraction of thorium and uranium ions from solid and liquid materials with fluorinated $\beta$-diketones and tributyl phosphate, Environ. Sci. Technol. 28 (1994) 1190.

[14] Y. Lin, C.M. Wai, Supercritical fluid extraction of lanthanides with fluorinated $\beta$-diketones and tributyl phosphate, Anal. Chem. 66 (1994) 1971.

[15] N.G. Smart, T.E. Carleson, S. Elshani, S. Wang, C.M. Wai, Extraction of toxic heavy metals using supercritical fluid carbon dioxide containing organophosphorus reagents, Ind. Eng. Chem. Res. 36 (1997) 1819.

[16] C. Kersch, G.F. Woerlee, G.J. Witkamp, An experimental study on the supercritical fluid extraction of heavy metals from sand, in: Proceeding of 6th Meeting on Supercritical Fluids Chemistry and Materials, Nottingham, 1999, p. 591.

[17] F. Gervais, C. Perre, S. Sarrade, P. Moszkowicz, L. Barna, Soils decontamination using supercritical $\mathrm{CO}_{2}$ : complexation and extraction of $\mathrm{Co}$ (II)-acetylacetonate, in: Proceedings of 6th Meeting on Supercritical Fluids Chemistry and Materials, Nottingham, 1999, p. 625.

[18] K.L. Toews, R.M. Scholl, C.M. Wai, N.G. Smart, pHdefining equilibrium between water and supercritical $\mathrm{CO}_{2}$. Influence on SFE of organics and metal-chelates, Anal. Chem. 67 (1995) 4040.

[19] C. Pommier, J.F. Bocquet, K. Chhor, M. Barj, Solubility and decomposition studies on organometallic compounds in supercritical fluids for ceramic precursor powder elaboration, J. Mater. Sci. May (1992) 353. 
[20] D.W. Matson, J.L. Fulton, R.C. Peterson, R.D. Smith, Rapid expansion of supercritical fluid solutions: solute formation of powders, thin films, and fibers, Ind. Eng. Chem. Res. 26 (1987) 2298.

[21] C.M. Wai, S. Wang, Supercritical fluid extraction: metals as complexes, J. Chromatogr. A 785 (1997) 369.

[22] J.M. Murphy, C. Erkey, Thermodynamics of extraction of copper(II) from aqueous solutions by chelation in supercritical carbon dioxide, Environ. Sci. Technol. 31 (1997) 1674

[23] M. Sharma, Extraction and reaction, in: M. Baird, C. Hanson (Eds.), Handbook of Solvent Extraction, Wiley Interscience, New York, 1983, p. 37.

[24] E.L. Cussler, Diffusion Mass-transfer in Fluid Systems, second ed., Cambridge University Press, New York, 1997, pp. $48-355$.

[25] R. Tayler, R. Krishna, Multicomponent Mass-transfer, Wiley, New York, 1993, p. 152.

[26] M.E. Paulaitis, V.J. Krukonis, R.T. Kurnik, R.C. Reid, Supercritical Fluid Extraction, Rev. Chem. Eng. 1 (1983) 179.

[27] K.A. Larson, J.M. Wiencek, Kinetics of mercury extraction using oleic acid, Ind. Eng. Chem. Res. 32 (1993) 2854.

[28] K. Larson, B. Raghuraman, J. Wiencek, Mass-transfer model of mercury removal from water via microemulsion liquid membranes, Ind. Eng. Chem. Res. 33 (1994) 1612.

[29] M.A. McHugh, V.J. Krukonis, Supercritical Fluid Extraction Principles and Practice, second ed., Butterworths, Boston, 1994.

[30] S.V. Gollakota, J.A. Guin, Comparative study of gas-liquid mass-transfer coefficients in stirred autoclaves, tubing bomb microreactors, and bubble columns, Ind. Eng. Chem. Process Des. Dev. 23 (1984) 52.

[31] K. Takahashi, A.W. Nienow, Bubble sizes, hold-up and coalescence rates in an aerated vessel agitated by a Rushton turbine: special variations, in: Proceedings of the 7th European Conference on Mixing, 1992, p. 285.

[32] M.B. King, T.R. Bott, M.J. Barr, R.S. Mahmud, Equilibrium and rate data for the extraction of lipids using compressed carbon dioxide, Sep. Sci. Tech. 22 (1987) 1103.

[33] N. Wakao, S. Kaguei, Heat and Mass-transfer in Packed Beds, Gordon and Breach, New York, 1982, p. 156.

[34] W.J. McManamey, S.K.S. Multani, J.T. Davies, Molecular diffusion and liquid-liquid mass-transfer in stirred transfer cells, Chem. Eng. Sci. 30 (1975) 1536.

[35] S.V. Save, S.S. Zanwar, V.G. Pangarkar, Solid-liquid mass-transfer to rotating impellers, Chem. Eng. Sci. 44 (1989) 1591.

[36] M.H. Al-Dahhan, C.E. Wicks, Influence of mixing intensity on the mass-transfer coefficient across liquid-liquid interfaces, Chem. Eng. Sci. 145 (1996) 213.

[37] R.B. Bird, W.E. Stewart, E.N. Lightfoot, Transport Phenonmena, Wiley, New York, 1960, p. 514.

[38] N.L. Carr, R. Kobayashi, D.B. Burroughs, Am. Inst. Min. Met. Eng, Petroleum Tech. 6 (1954) 47.

[39] K.A.M. Gasem, K.B. Dickson, P.B. Dulcamara, N. Nagarajan, J. Robinson, Equilibrium phase compositions, phase densities, and interfacial tensions for $\mathrm{CO}_{2}+$ hydrocarbon systems. 5. $\mathrm{CO}_{2}+n$-tetradecane, J. Chem. Eng. Data 34 (1989) 191.

[40] H.H. Tsai, Effluent Standards, Environmental Protection Administration of the Republic of China on Taiwan, November, 1999. 